\title{
2006-1207: CURRENT RESEARCH THRUSTS IN CIVIL AND ENVIRONMENTAL ENGINEERING AND IMPLICATIONS FOR EDUCATION: A BIG 10+ PERSPECTIVE
}

\section{Ronald Harichandran, Michigan State University}

Ronald Harichandran is professor and chairperson of the Department of Civil and Environmental Engineering at Michigan State University (MSU). He has been chairperson since 1995 and is a Fellow of ASCE. His department leads the largest engineering-based study abroad programs in the country. He currently serves on the ASCE Department Heads Council Executive Committee, the Accreditation Committee of the ASCE Committee on Academic Prerequisites for Professional Practice, and the ASCE Body of Knowledge II Committee. He is the inaugural chair of the Michigan Transportation Research Board. 


\section{Current Research Thrusts in Civil and Environmental Engineering and Implications for Education: A Big 10+ Perspective}

\section{Introduction}

Civil and environmental engineering (CEE) is evolving so as to remain at the forefront of new developments aimed at enhancing the built and natural environments. Such evolution is not new for CEE, but it currently is occurring at a faster pace and encompasses a wider range of areas than has been the case hitherto. CEE must necessarily embrace the use and development of new technological breakthroughs that are constantly taking place to address social problems in an increasingly complex, globally connected, and congested world. This white paper outlines a perspective of current research thrusts in CEE, and touches on their implications for CEE education. The perspective was formed by a group of CEE department chairs/heads from the so-called Big 10+ universities.

In June 2004, Nikolaos Katopodes, CEE chair at the University of Michigan, called the chairs/heads of CEE departments in the Big 10+ universities, perhaps for the first time, to gather at Northwestern University to delineate the common interests of research-intensive universities. A common element of the Big 10+ universities is their emphasis on research. There are several other leading research universities outside of the Big 10+ umbrella who also need to provide input toward composing a collective vision for the profession. For the moment, however, the Big $10+$ universities provide a convenient framework to begin this discussion.

The Big 10+ group decided to focus its effort on composing a collective vision for CEE research thrusts into the foreseeable future. This paper is intended to broadly engage the CEE profession in an important discussion about CEE research thrusts, education, practice, and accreditation.

\section{Current Research Thrusts}

Current research thrusts in engineering are dominated by the infusion of nanotechnology, bioengineering and information technology into the more traditional disciplines. There is significantly greater opportunity to secure research grants from federal funding agencies, such as the National Science Foundation (NSF), for work that focuses on these new technologies. For example, a recent $\mathrm{SBIR}^{1}$ program announcement from NSF related to Security Technologies states: "The mission of NSF is to promote the progress of science; to advance the national health, prosperity, and welfare; and to secure the national defense. In support of this mission and consistent with the FY05 Interagency Research and Development Priorities announced by the Director of the Office of Science and Technology Policy, the NSF SBIR/STTR ${ }^{2}$ program will solicit crossdisciplinary proposals to address specific opportunities that enhance the United States of America's security. Under this solicitation, NSF will support priority areas that are addressed by the convergence of at least two of the following three technologies: nanotechnology, biotechnology and information technology (both hardware and software).,

\footnotetext{
${ }^{1}$ Small Business Innovation Research

${ }^{2}$ Small-business Technology Transfer Research

${ }^{3}$ www.nsf.gov/eng/sbir/Security.jsp
} 
The opinion is sometimes expressed that it is difficult for civil and environmental engineers to embrace these new technologies. However, many of the CEE programs in the Big 10+ universities are doing just that. Further, they are using these technologies to solve the infrastructure and environmental problems faced by today's society, are adopting a system-integration view of the built and natural environments, and are embracing the concept of sustainability.

\section{Vision for CEE Research}

Civil and environmental engineers work on complex, large-scale systems that improve the built and natural environments. Typically, these systems are unique, insofar that they must take into account diverse considerations associated with technical developments and their implications, prevailing local conditions, as well as available resources and talents. This is a monumental task, and CEE's innate breadth reflects the many areas of expertise required to accomplish it. Inevitably, each CEE department in the country is characterized by its particular focus and strength.

The Big 10+ CEE department chairs named in this document provided several ideas regarding current research trends, and thereby to project a vision for the future. Some chairs provided their own detailed vision documents, whereas others loosely sketched out their views. The principal elements of these visions and views are captured and categorized in Figure 1.

Figure 1 suggests the need for flexible alignment and focusing of CEE research programs, as well as of CEE education. Civil and environmental engineering faculty perform research related to the built and the natural environments, and until recently have focused their work in the now traditional sub-disciplines labeled construction, environmental, geotechnical, materials, pavement, structural, transportation and water resources engineering. However, partly in response to technological developments, and commensurate changes in federal funding priorities, realignments are taking place. Faculty are working in a variety of pertinent interdisciplinary areas, such as environmental biotechnology, environmental and infrastructure sensors and sensor networks, hydrological and ecological interactions, geoenvironmental engineering, multi-scale analysis, multi-hazard mitigation, and computer integrated construction.

A key concept emerging within CEE is the issue of sustainability. The integration of built and natural systems must be sustainable in the long-term with respect to environmental, economical, and social considerations. The concept of sustainability poses a new set of research (and education) issues that must be addressed. The Big 10+ group sees the need for a common set of mathematical, sensing, modeling, computational, molecular biology and chemical tools that can be used to address issues related to both the built and natural environments. Figure 1 conveys a sense of the broad research (and education) framework implied by this view.

\section{Attracting Students}

Attracting talented students is among the primary challenges faced by CEE departments in grasping the opportunities availed by the current research thrusts. At the undergraduate level CEE departments compete for students who have a general interest in engineering. There is a need to create a sense of excitement about CEE. This challenge occurs at a time when students are widely exposed to and easily enamored by consumer electronics, computers and sophisti- 
cated automobiles throughout their childhood. Therefore, CEE departments must show that such high profile concerns as environmental conservation, renewable energy, the application of new materials and technical systems, along with the overall concern for sustainable development, provide stimulating career opportunity for CEE students. In particular, these concerns offer a platform for CEE to recruit young and idealistic minds interested in contributing toward solving some of society's vital fundamental concerns. The prospect of using emerging technologies to address sustainable development has the definite potential of exciting undergraduate students.

Several initiatives in this regard are already underway. Stanford University, for instance, is planning to provide an innovative experience to students by establishing a residential program in a newly constructed "green" dormitory building. The building is expected to showcase sustainable concepts related to energy, water systems, vehicle refueling, air quality, etc. and serve as a "live-in laboratory."

The new thrusts are driving curriculum reform. Several Big 10+ CEE departments have developed new courses that address these emerging priorities. Such courses include substantial aspects of sustainability, preservation of civil infrastructure, nanotechnology, sensor technology, biotechnology, intelligent transportation systems, and the application of new materials. Additionally, student organizations that focus on concepts of sustainability (e.g., Engineers Without Borders) are rapidly growing in popularity on campuses.

A further challenge is the recruitment of talented graduate students, especially at the Ph.D.degree level. Although students are more set in their disciplines by the time they obtain the B.S. degree, the recruitment of Ph.D. students, especially domestic ones, remains a difficult proposition. The M.S. degree provides most domestic students with the skills they need to function in CEE practice. Consequently, few domestic students see the need, or have the desire, to secure the Ph.D. degree. This situation poses a serious problem for research-intensive universities, who up to now have relied on international students as the main cadre of Ph.D. programs in most CEE departments. It is a situation that likely will worsen, because the recruitment pool of international students is decreasing in response to the improving economies in the Far East, China and India, the development of research-intensive universities in those regions, and U.S. visa restrictions. Therefore, as competition for Ph.D. students increases, it is imperative that the stimulating concerns engaging CEE research are sufficiently publicized so as to draw potential Ph.D. students into $\mathrm{CEE}$ research efforts.

\section{Risk of Dichotomy between Research and Practice}

At the same time that CEE's research thrusts are evolving, CEE as a profession is engaged in an effort to define the education requirements for future engineers who will meet the needs of CEE practice. As practice usually lags research, it is important to maintain effective linkages between the two, and to avert the risk of a dichotomy arising between the needs of research and practice.

As CEE research activities become more interdisciplinary, faculty and students engaged in research need to be conversant with a variety of subject areas not traditionally considered as being a major part of CEE programs. These areas include biology, chemistry, biochemistry, ad-

vanced computing, electrical engineering, nanotechnology, information technology, materials 
science at multi-scales, and systems science. However, the inclusion of faculty with expertise in these new areas raises adjustment issues with which departments must cope. For example, one issue related to undergraduate education concerns the competency of such faculty to teach engineering design. New faculty engaged in certain emerging areas come from programs focused on scientific research, and thus may not have a strong engineering design background.

The Civil Engineering Body of Knowledge for the $21^{\text {st }}$ Century ${ }^{1}$ and The Engineer of 2020: Visions of Engineering in the New Century ${ }^{2}$ document a call for broadly trained civil engineers conversant not only with mathematics, science and design, but also multi-disciplinary teams, professional ethics, communications, globalization, life-long learning, contemporary issues, project management, construction, asset management, business and public policy and administration fundamentals, and leadership principles. Further, there is a push by the CEE profession overall to promote change in university undergraduate curricula by revising the basic civil engineering accreditation criteria to embrace as much of the breadth as possible. This push, however, is coming at a time of increased pressure to reduce the number of credit hours for the B.S. degree to 120 from the current 128-130+ in many programs. To make room for increased breadth, while maintaining technical depth, the attainment of an M.S. degree or 30-credits worth of post-secondary education is being encouraged, with the long-term view that this extent of post-baccalaureate education will be required for licensure as a practicing civil and/or environmental engineer. ${ }^{3}$

The differing needs of CEE research and CEE practice can create particular problems for research-intensive CEE departments, especially for those that are small to medium in size and located in non-metropolitan settings. Delivering a broad undergraduate program that includes multi-disciplinary teams, professional ethics, communications, project management, construction, asset management, business and public policy and administration fundamentals, and leadership principles requires faculty with a broad portfolio of expertise, or the effective use of adjunct faculty drawn from practice. It also is possible to utilize courses in other departments of a university to fulfill some of the breadth requirements, but unless courses are well-packaged this often consumes too many credits. The development of research based on emerging technologies requires faculty with expertise in non-traditional areas, sometimes at the expense of expertise in more traditional areas. This increases the growing disconnect between the current (traditional) undergraduate curriculum and the research interests of faculty seeking to prosper in the current funding environment. Large CEE departments, or those in metropolitan settings with the ability to involve practicing engineers in teaching, are better positioned to balance these conflicting needs. Small to medium-size research-intensive CEE departments in non-metropolitan settings are particularly conflicted by these dichotomous needs.

The needs imposed by the future research landscape and those imposed by the future practice landscape are equally important. Addressing only one set of these needs would endanger $\mathrm{CEE}$ as a profession. Yet, CEE must compete effectively in the national research arena, or it will lose standing within the broader engineering discipline and be deemed no longer a vibrant profession. This alarming prospect would endanger the education of future civil engineers. A field of study perceived as not participating at the forefront of science and engineering will fail to attract talented students. In accordance with this concern, CEE must adjust its educational pro-

\footnotetext{
${ }^{1}$ www.asce.org/professional/educ/bodyofknowledge.cfm, ASCE, Reston, Virginia, 2004

${ }^{2}$ National Academy of Engineering, Washington, D.C., 2004

${ }^{3}$ www.asce.org/pdf/fpd-execsumm.pdf
} 
grams at the undergraduate and graduate levels so that future civil and environmental engineers acquire the attributes needed for them to be effective professionals in a complex, globally connected, and congested world.

So what is the solution to this risk of dichotomy? It is the view of the Big 10+ group that a more flexible evolving approach to education is absolutely necessary for CEE to remain vibrant and relevant both in research and practice. CEE programs in universities must be allowed the flexibility to establish their own strengths while meeting a minimum set of standards developed by the CEE profession as a whole. Accreditation criteria, such as those used for engineering programs by the ABET, ${ }^{1}$ should promote this flexibility, encourage diversity in curricula, be cautious about emphatic prescription of curriculum, and yet ensure that the essential engineering competencies are achieved. In this respect, it is important that faculty from research-intensive CEE departments who have a research-oriented view be actively engaged in formulating ABET accreditation criteria, in evaluating programs being considered for accreditation, and in performing the academic review of departments. This participation is necessary to ensure that appropriate flexibility is maintained for the well-being of CEE as a profession.

\section{Current Efforts Aimed at Alleviating the Risk of Dichotomy}

The Civil Engineering Body of Knowledge for the $21^{\text {st }}$ Century (BOK) is presently in the process of being revised by a Body of Knowledge II Committee formed under the auspices of the ASCE Committee on Academic Prerequisites for Professional Practice $\left(\mathrm{CAP}^{3}\right)$. Researchoriented CEE faculty and chairs from research intensive universities are well-represented on this committee, and some of the issues presented above are being discussed. For example, the following topics are amongst several presently under consideration for inclusion in the second edition of the BOK: sustainability, globalization, emerging technologies, discovery mode of learning, specialization, and risk/uncertainty. While specific recommendations are yet to emerge and be finalized, the following ideas on revising civil engineering undergraduate and MS programs are being discussed: ${ }^{2}$

- Sustainability concepts should be included in design courses. Sustainability can be taught by associating a cost and time scale to engineered solutions, whether this is 10 years or 100 years. Students should be cognizant of the life of engineered systems, and the cost associated with building and maintaining them in terms of dollars, impact on the environment, impact on resources, and political impact. This can be done within the context of existing design courses in a curriculum. Professional organizations such as ASCE and ASEE have issued position statements related to this.,

- Students should be prepared for a global work environment. This can be accomplished through study abroad, research at foreign institutions, internships abroad, developing the ability to communicate in languages other than English, team-based work with members in foreign countries, study of foreign literature, and interaction with students/colleagues from foreign countries.

\footnotetext{
${ }^{1}$ Accreditation Board for Engineering and Technology

${ }^{2}$ Taken from the Body of Knowledge II Committee's working documents

${ }^{3}$ ASCE Policy Statement $418<$ http://www.asce.org/pressroom/news/policy_details.cfm?hdlid=60>

${ }^{4}$ ASEE Sustainable Development Education statement $<\mathrm{http}$ ://www.asee.org/about/statementSustain.cfm $>$
} 
- Undergraduate students should be able to explain the use of new materials and emerging technologies in civil engineering applications. Knowledge of new materials and emerging technologies such as biotechnology, information technology, nanotechnology, etc. is important so that innovative future solutions to civil engineering problems can be promoted.

- In order to train students to think creatively when devising solutions to civil engineering problems, they need to be exposed to learning through discovery. Activities that foster learning through discovery include undergraduate research, inquiry-based learning in classes, and the solution of unstructured and open-ended problems.

- Specialized knowledge and skills beyond that normally included in the traditional fouryear bachelor's degree is essential for entry into the practice of civil engineering. This specialization could be in traditional or emerging areas. Civil engineering specializations in non-traditional, boundary, or emerging fields such as ecological engineering, nanotechnology, biotechnology, information technology, etc. will require courses outside the traditional civil engineering graduate curriculum such as math and science, unique or advanced engineering science courses, and other specialized technical coursework. Regardless of the specific path toward attainment of technical specialization, tangible relation to the professional practice of civil engineering should be required.

- Students should understand concepts of risk and uncertainty in civil engineering. There are unavoidable uncertainties in any engineering design and in decision-making. These can be data-based (known as aleatory type) and knowledge-based (known as epistemic type). Students should be able to recognize and quantify those uncertainties as part of the design process, and apply probabilistic and statistical tools to quantify the risk of failure, which could impact the health and welfare of the public and the environment.

Revision of CE undergraduate and MS curricula to include many of the above recommendations are sure to take place after the second edition of the BOK document is finalized.

\section{Conclusions}

Civil and environmental engineering has an exciting future, as CEE more than any other profession deals directly with the broad range of basic human needs (sustenance, housing, health, movement, environmental well-being). However, to succeed in a substantially evolving research landscape, civil and environmental engineers need to acquire the knowledge required to solve problems in an increasingly complex, globally connected, and congested world. Accordingly, CEE departments need to facilitate suitably adaptable research and education programs that fulfill the needs of CEE as a profession. To succeed at this, CEE departments must create exciting opportunities for undergraduate and graduate students, and must be afforded the flexibility needed to establish their mark of excellence.

\section{Acknowledgements}

The following people provided input in the development of this paper: Robert Dodds, Jr., Head of CEE, University of Illinois at Urbana-Champaign; Robert Ettema, Chair of CEE, The University of Iowa; Gregory Fenves, Chair of CEE, University of California at Berkeley; John Gulliver, Head of CE, University of Minnesota; Chris Hendrickson, Chair of CEE, Carnegie Mellon University; Joseph Hughes, Chair of CEE, Georgia Institute of Technology; Patrick Jail- 
let, Head of CEE, Massachusetts Institute of Technology; Hamlin Jennings, Chair of CEE, Northwestern University; Nikolaos Katopodes, Chair of CEE, University of Michigan; Richard Luthy, Chair of CEE, Stanford University; Jeffrey Russell, Chair of CEE, University of Wisconsin at Madison; Andrew Scanlon, Head of CEE, Pennsylvania State University; Gerald Speitel, Jr., Chair of CEE, University of Texas at Austin; the ASCE Body of Knowledge II Committee. 


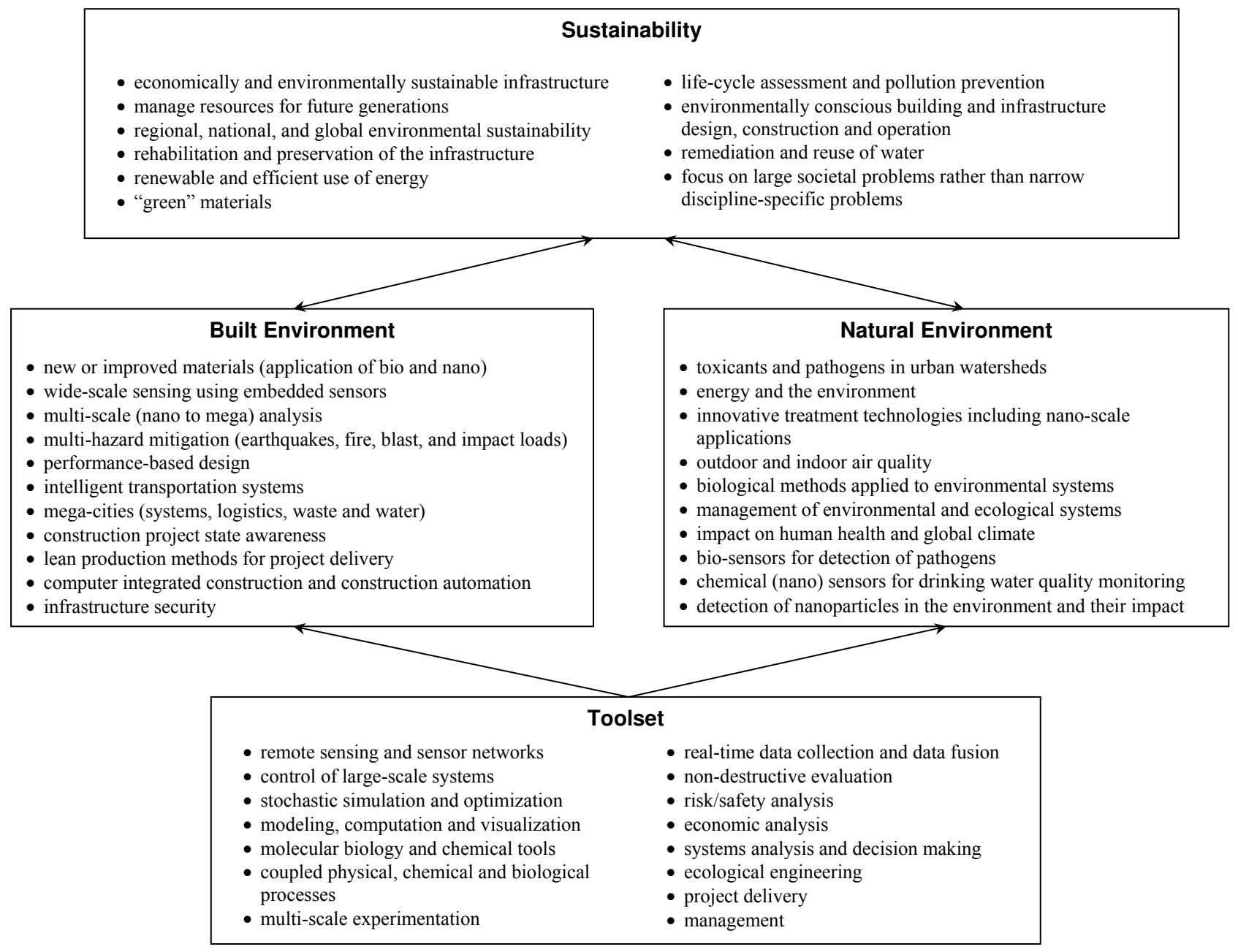

Figure 1. A research framework for civil and environmental engineering 